\title{
Editorial
}

\section{Quadriénio 2018-2021 - Balanço de uma Presidência}

\section{8-2021 Quadrennium - Review of a Presidency}

\author{
João Carlos Sampaio Fernandes ${ }^{1, *}$ \\ ${ }^{1}$ Presidente da Direção da Sociedade Portuguesa de Estomatologia e Medicina Dentária (SPEMD)
}

No passado dia 11 de dezembro decorreram as eleições para os órgãos sociais da Sociedade Portuguesa de Estomatologia e Medicina Dentária (SPEMD). Apresentou-se a sufrágio uma lista, tendo sido eleitos 33 colegas, que integram a Assembleia Geral (Presidente: Professora Ana Azul), o Conselho Fiscal (Presidente: Professora Maria Helena Figueiral), a Direção Nacional (Presidente: Professor Duarte Marques), e os três Conselhos Regionais (Norte - Presidente: Dr. João Bravo; Centro Presidente: Professora Ana Messias; Sul - Presidente: Professor João Silveira).

Cumpridos dois mandatos como Presidente da Direção Nacional da SPEMD, felicito vivamente todos os colegas e amigos agora eleitos.

Gostaria, também, de manifestar a todos os membros dos órgãos diretivos e sociais, que agora cessam funções, que foi uma honra muito grande contar com a colaboração, apoio e confiança de todos na defesa da Sociedade e dos seus sócios.

Num mandato marcado por tempos difíceis, agravados pela crise resultante da pandemia da COVID-19, é de realçar que a SPEMD tenha conseguido continuar a honrar os seus pergaminhos em termos globais, nomeadamente na formação (cursos e congressos; publicação regular da Revista) e na representação ativa dos seus associados na FDI - Federação Dentária Internacional.

Um agradecimento especial aos colegas dirigentes e associados das Sociedades Parceiras e Afiliadas da SPEMD, pela sua inestimável colaboração, assim como à Sr. ${ }^{a} \mathrm{D}$. Sofia Rosário, funcionária da SPEMD, pela sua elevada competência e dedicação.

Certo de termos servido a SPEMD com todo o nosso esforço, e de ainda continuarmos em funções até à posse dos membros eleitos a decorrer em março de 2022, vamos dar início, desde já, a uma transição gradual de responsabilidades, com o objetivo de continuar a contribuir para engrandecimento desta Sociedade Científica e para a dignificação da Medicina Dentária e da Estomatologia Portuguesas.

À nova equipa da SPEMD, na pessoa do colega Duarte Marques, novo Presidente Eleito da SPEMD, desejo as maiores felicidades para o mandato que irão iniciar, de forma a tornar a Sociedade cada vez mais importante para a formação humana, profissional e científica dos seus associados.

A todos o meu reconhecido obrigado.

\footnotetext{
${ }^{*}$ Autor correspondente.

Correio eletrónico: sampaiofernandes@gmail.com (João Carlos Sampaio Fernandes).

http://doi.org/10.24873/j.rpemd.2021.12.856

1646-2890/@ 2021 Sociedade Portuguesa de Estomatologia e Medicina Dentária. Published by SPEMD.

This is an open access article under the CC BY-NC-ND license (http://creativecommons.org/licenses/by-nc-nd/4.0/).
} 